Kyoto University,

Graduate School of Economics

Research Project Center Discussion Paper Series

\title{
Optimal Rules of Origin with Asymmetric Compliance Costs
}

\section{under International Duopoly}

\author{
Naoto Jinji \\ Yoshihiro Mizoguchi \\ Discussion Paper No. E-14-016 \\ Research Project Center \\ Graduate School of Economics \\ Kyoto University \\ Yoshida-Honmachi, Sakyo-ku \\ Kyoto City, 606-8501, Japan
}

February, 2015 


\title{
Optimal Rules of Origin with Asymmetric Compliance Costs under International Duopoly*
}

\author{
Naoto JINJI \\ Kyoto University
}

\author{
Yoshihiro MIZOGUCHI ${ }^{\ddagger}$ \\ Teikyo University
}

\begin{abstract}
We examine the optimal rules of origin (ROO) in a free trade area/agreement (FTA). We incorporate compliance costs of the ROO into the model. In particular, compliance costs are higher for a firm located in a non-member country of the FTA than for a firm located in an FTA member country, whereas marginal production costs are lower for the former. An importing country within the FTA imposes tariffs on imports that do not comply with the ROO. We show that the optimal ROO may have a protectionist bias or cause low utilization of FTAs depending on parameter values.
\end{abstract}

Keywords: free trade area/agreement; rules of origin; compliance costs; oligopoly; double rent-shifting

JEL Classification: F12; F15.

\footnotetext{
${ }^{*}$ We thank Jota Ishikawa, Hiroshi Mukunoki, Kazuhiro Takauchi, Binh Tran-Nam, and participants of the 4th Spring Meeting of the Japan Society of International Economics, the Fall 2014 Meeting of the Japanese Economic Association, the 3rd HITS-MJT Seminar on International Economy and Industry, and Kobe International Conference on "Fragmentation, Time Zones, and their Dynamic Consequences" for their helpful comments and suggestions on earlier versions of the paper. Jinji acknowledges financial support from the Japan Society for the Promotion of Science under the Grant-in-Aid for Scientific Research (B) No. 23330087 and (C) No. 24530246. The authors are solely responsible for any remaining errors.

${ }^{\dagger}$ Corresponding author. Faculty of Economics, Kyoto University, Yoshida-honmachi, Sakyo-ku, Kyoto 606-8501, Japan. Phone \& fax: +81-75-753-3511. E-mail: jinji@econ.kyoto-u.ac.jp

${ }^{\ddagger}$ Department of Regional Economics, Teikyo University, 1-1 Toyosatodai, Utsunomiya, Tochigi 320-8551, Japan.
} 


\section{Introduction}

The world economy has witnessed a rapid proliferation of regional trade agreements (RTAs) over the last two decades. Most of the RTAs that are currently in force take the form of a "free trade area/agreement" (FTA). In contrast to a "customs union" (CU), in which member countries have to set common external tariffs, each member of an FTA has the freedom to maintain its own external tariffs. As there may be heterogeneity in external tariffs among members of an FTA, firms in non-member countries have an incentive to export their goods to member countries with the lowest external tariffs and re-export them to other member countries with higher external tariffs. To prevent such tariff circumvention, FTAs usually set rules of origin (ROO), which specify detailed conditions under which goods are regarded as produced within the FTA so that they are eligible for trade among members of the FTA without tariffs. ${ }^{1}$

Despite its legitimate reason for utilization in FTAs, the ROO have been criticized for their protectionist effects (Krueger, 1999; Krishna and Krueger, 1995). Krueger (1999) argues that the ROO induce final good producers in member countries of an FTA to shift their sources of intermediate inputs from low-cost non-member countries to high-cost member countries to make their products eligible for tariff-free exports to other member countries. The ROO may also generate another protectionist bias if they are set such that producers in FTA member countries have an incentive to comply and those in non-member countries do not.

Another issue regarding the ROO pointed out more recently is related to the rates of FTA utilization by producers in FTA member countries. In fact, the rate of utilization is surprisingly low for some FTAs. For example, Anson et al. (2005) report that the utilization rate of the North American Free Trade Agreement (NAFTA) for Mexican exports to the United States (US) was 64\% in 2000. According to James (2008), the utilization rate of the US-Chile FTA for Chilean exports to the US in 2005-2006 was about 55\%. The utilization rate is much lower for FTAs in Asia (Hayakawa et al., 2013). Utilization of the ASEAN Free Trade Area (AFTA) for exports of Japanese firms and their affiliates operating in ASEAN countries was only 15-20\% during the period 2003-2006. One possible reason for such low utilization rates of FTAs is that firms are reluctant to incur additional costs to comply with the ROO. The use of preferential tariff rates under FTAs requires firms to comply with the ROO specified in the FTAs, "to obtain certificates of origin (COO) in exporting countries and to submit the COO to the customs in importing countries" (Hayakawa et al., 2013: 246). The procedures

\footnotetext{
${ }^{1}$ Basically, there are three criteria of the ROO to check whether a "substantial transformation" of goods is done within the FTA (Falvey and Reed, 1998): changes in tariff classification (CTC), value-added content (VC), or specific production process (SP). The CTC criterion requires that imported intermediate inputs be transformed into products with different tariff classifications within the FTA. The VC criterion specifies a minimum percentage of value that should be added within the FTA. Finally, the SP criterion specifies certain production or processing that should be conducted within the FTA.
} 
that firms have to follow to utilize the FTAs' preferential tariff rates generate additional production and administrative costs. Anton et al. (2005) provide empirical evidence that the compliance costs of ROO are not negligible. ${ }^{2}$ Firms located in FTA member countries, as well as those in non-member countries, incur compliance costs (Augier et al., 2005; Cadot and de Melo, 2008). For example, when firms in FTA members initially import intermediate inputs from FTA non-members, they may partly change the source of the intermediate inputs from non-members to members, with possibly higher prices. In addition, compliance costs will be generally higher as the ROO are more stringent.

In this paper, we examine whether the ROO that are optimally set by FTA member countries involve a protectionist bias and, also, cause low utilization of FTAs. We focus on the effects of asymmetric compliance costs of ROO between firms of FTA members and non-members on market competition among firms. We employ a stylized three-country partial equilibrium model of an international duopoly. Unlike previous studies in the literature of ROO (e.g., Falvey and Reed, 2002; Ju and Krishna, 2005; Chang and Xiao, 2013; Takauchi, 2014), however, we construct a simple model in which the intermediate input market is abstracted and directly introduce compliance costs of ROO into firms' cost functions. This simple approach allows us to identify the optimal choice of ROO for FTA members, combined with the external tariff set by an FTA member, by analyzing the relationship between asymmetric compliance costs of ROO among firms and their behaviors in a tractable way. The basic structure of our model is as follows. Two firms produce a homogeneous good and compete in a Cournot fashion in a market located in one of two FTA member countries (country A). One of the two firms (firm $I$ ) is located in an FTA member country (country B), which is different from the country in which the market is located (country A), and another firm (firm E) is located in an FTA non-member country (country C). Firm $I$ is more inefficient than firm $E$; hence, its marginal production cost is higher than that of firm $E$. Country A imposes its own external tariffs on imports. However, it imports goods without tariffs if they comply with the ROO of the FTA. Both firms $E$ and $I$ can comply with the ROO by incurring compliance costs. Firm $I$ has some advantage in complying with the ROO compared with firm $E$; hence, firm $E$ must incur relatively higher compliance costs. The FTA member countries (i.e., countries A and B) set the stringency of ROO to maximize their joint welfare. More stringent ROO impose higher compliance costs on firms.

We consider a four-stage game. In stage 1, the member countries (A and B) set the optimal level of ROO to maximize joint welfare of countries A and B. In stage 2, country A sets its external tariffs to maximize domestic welfare. Here, we explicitly take into account the restriction imposed by GATT Article XXIV that country A's external tariff should not be raised above the pre-FTA level. In stage

\footnotetext{
${ }^{2}$ Anton et al. (2005) find that in the case of the NAFTA, the average compliance costs are around $6 \%$ in ad valorem equivalent. As a related issue, there exists considerable empirical literature on the compliance costs of taxation. See, for example, Andreoni, Erard, and Feinstein (1998), Tran-Nam et al. (2000), and Mathieu, Waddams Price, and Antwi (2010).
} 
3 , the two firms simultaneously decide whether to comply with the ROO. In stage 4 , they compete in country A's market in a Cournot fashion.

The main results are as follow. The equilibrium outcome depends on both the degree of the relative cost disadvantage of firm $I$ and the degree of relative disadvantage of firm $E$ in complying with the ROO. First, when the marginal cost of firm $I$ is sufficiently higher than that of firm $E$, the optimal ROO are set to induce firm $I$ to comply and firm $E$ not to comply with the ROO. Second, when the cost disadvantage of firm $I$ is at a medium level, the optimal ROO is set to induce both firms not to comply with the ROO if the disadvantage of firm $E$ in compliance costs is less serious and to induce only firm $I$ to comply with the ROO if the disadvantage of firm $E$ in compliance costs is serious. Finally, when the cost difference between the two firms is relatively small, the optimal ROO are set to induce, again, only firm $I$ to comply with the ROO if firm $E$ 's compliance costs are sufficiently higher than that of firm $I$ and to induce both firms to comply with the ROO if the difference in compliance costs between the two firms is also relatively small. Thus, our analysis reveals that ROO involve a protectionist bias in the sense that they are set for only firm $I$ to comply if firm $I$ 's marginal cost is sufficiently higher or the difference in compliance costs of ROO between the two firms is sufficiently large. Our results also explain low utilization of FTAs due to the ROO for a medium range of cost disadvantage for firm $I$ and a small difference in compliance costs between the two firms, in which the ROO are set such that neither firm complies with them. The reason why the joint welfare of the FTA members becomes higher when only firm $I$ complies with the ROO is not as straightforward as expected. Actually, different mechanisms work, depending on the case. We argue that in case of a relatively small cost disadvantage of firm $I$ and a medium difference in compliance costs, double rent-shifting improves FTA members' welfare by shifting rents from firm $I$ to firm $E$ and shifting rents back by imposing tariffs. To our knowledge, this mechanism is new to the literature. On the other hand, for a range of medium cost disadvantage of firm $I$, the ROO enable FTA members to liberalize trade preferentially; hence, a rent-shifting effect from firm $E$ to firm $I$ and a pro-competitive effect improve members' welfare.

Though there are a number of existing studies related to our paper, our analysis and results differ from these. First, as mentioned above, Krueger (1999) and Krishna and Krueger (1995) illustrate the protectionist effects of ROO, which distort the demand for intermediate inputs. ${ }^{3}$ In contrast, we focus on a possible protectionist bias in the final-good market in the sense that the ROO are arranged by FTA members so that only internal firms have an incentive to comply. Similar to this study, the strategic interactions among firms in final-good markets is the center of the analysis in Ishikawa, Mukunoki, and Mizoguchi (2007). However, their focus is quite different from ours. They consider Bertrand competition between an internal and an external final-good producer of an FTA and illustrate anti-competitive and anti-protectionist effects of ROO due to the market power mitigation

\footnotetext{
${ }^{3}$ Rosellón (2000) also analyze the effects of ROO on the intermediate-good market and welfare.
} 
for the internal firm. However, in their model, goods produced by the internal firm always qualify for tariff-free exports, and goods produced by the external firm have no option to comply with the ROO in the presence of ROO.

Second, Ju and Krishna (2005) and Takauchi (2014) address the issue of low FTA utilization rates due to ROO. Under perfect competition, Ju and Krishna (2005) show that in response to the restrictiveness of the ROO, all or only a fraction of the firms in an FTA comply with the ROO at equilibrium. Depending on the type of equilibrium, more stringent ROO may raise or reduce the demand for inputs manufactured within the FTA. The effects of ROO on market access by firms outside the FTA also depend on the type of equilibrium. Takauchi (2014) considers the case in which a monopolist supplies intermediate inputs within an FTA. As the input price charged by the monopolist is affected by the number of firms that try to comply with the ROO, a strategic interaction among final-good producers in the FTA may result in an equilibrium in which compliers and non-compliers coexist. Whereas both studies focus on possible non-compliance by internal firms of an FTA, we consider the case in which both internal and external firms have the option of compliance or noncompliance and show that ROO may be set to induce even the internal firm to choose non-compliance for certain parameter values.

Finally, Falvey and Reed (2002) and Chang and Xiao (2013) are closely related to this paper. Both studies investigate policy combinations of optimal external tariffs by individual FTA members and ROO in FTAs. However, these two studies are still different from us in some important respects. Similar to this paper, Falvey and Reed (2002) consider the case in which there are one importing country and two exporting countries, and wherein the importing country forms an FTA with one of the two exporting countries. In the situation where the importing country has an incentive to impose discriminatory tariffs on imports from the two different countries, the ROO specifying the minimum share of domestically produced intermediate inputs in the exporting country determines whether the goods qualify for preferential tariffs. However, they assume that the importing country unilaterally sets the optimal ROO and tariffs and examine how the importing country will change the stringency of the ROO after forming an FTA (i.e., in response to a marginal reduction in tariffs imposed on one exporting country). They also ignore the possibility of non-compliance. In these respects, their focus is quite different from ours. ${ }^{4}$ On the other hand, as in our paper, Chang and Xiao (2013) consider that in a three-country model of trade under international oligopoly, FTA members jointly set the ROO and individually choose their optimal external tariffs. They analyze the effects of an FTA with ROO on equilibrium variables and showed how the optimal external tariffs are related to the restrictiveness of ROO. However, there are a number of key differences between their study and ours. First, they limit the choice of optimal external tariffs to the case of full compliance by internal firms. Second, in their model, external firms cannot comply with the ROO. This assumption is important because FTA

\footnotetext{
${ }^{4}$ In addition, they assume perfect competition, which is also different from our model setting.
} 
members can always earn tariff revenues from non-members as long as imports from non-members are positive. Third, there is no heterogeneity in compliance costs among firms in their study. Fourth, they only derive the range of ROO restrictiveness that improves welfare of each FTA member and do not analyze the optimal choice of ROO.

Given the abovementioned differences between this and previous studies, our study contributes to the ROO literature in at least two respects. First, we derive optimal policy combinations of ROO for FTA members, as a whole, and external tariffs for the importing country within the FTA when both internal and external firms have options of compliance and non-compliance. Second, we illustrate that the optimal ROO may actually have protectionist bias and also cause low utilization of FTA in one model, depending on the parameter values.

The remainder of the paper is organized as follows. In Section 2, we present the model setup. In Section 3, we analyze the equilibrium prior to forming an FTA. In Sections 4 and 5, we solve the model and analyze the optimal ROO. In Section 6, we present the conclusions.

\section{The Model}

We consider a simple three-country world. There are three countries: A, B, and C. Countries A and B form an FTA. Country C can be thought of as the rest of the world. Two firms (firms $I$ and $E$ ) produce a homogeneous good. Firm $I$ (the internal firm) is located in country B, and firm $E$ (the external firm) is located in country C. Let $x$ be the output of firm $I$ and $y$ be the output of firm $E$. We assume that firm $E$ has superior technology compared with firm $I$, which is represented by a lower marginal cost. Assuming that the marginal costs of production are constant, we normalize firm E's marginal cost to zero. Let $c>0$ be firm I's marginal cost.

For simplicity, we assume that the market for the good is located only in country A. The inverse demand for the good in country A's market is given by

$$
p=a-(x+y)
$$

where $p$ is the price of the good and $a>c$ is a parameter.

Country A imposes a specific tariff $t$ on imports. The FTA between countries A and B specifies the ROO. Even imports from country B are subject to country A's external tariff $t$ if they do not comply with the ROO. Conversely, even firm $E$ has a chance to export its goods to country A free of tariffs by complying with the ROO. However, each firm incurs "compliance costs" to comply with the ROO. For example, the ROO may specify a minimum share of inputs produced within the FTA that are more expensive than those produced in country C. The cost difference by increasing the share of inputs purchased within the FTA to comply with the ROO specification represents the compliance costs related to the $\mathrm{ROO}$. 
We assume that the compliance cost is lower for firm $I$ than for firm $E$. This may be because firm $I$, located within the FTA, has better access to intermediate inputs produced within the FTA or may have better knowledge about the administrative procedure of ROO. ${ }^{5}$ Let $\phi \geq 0$ be firm I's compliance cost per unit of output and $k \phi$ be firm $E$ 's compliance cost, where $k>1$. Since more stringent ROO require higher compliance costs, the level of $\phi$ can be interpreted as measuring the stringency of the ROO.

We consider a four-stage game. In stage 1, the FTA member countries (A and B) set the level of ROO $\phi$ to maximize their joint welfare. In stage 2, country A sets its external tariff $t$ to maximize its domestic welfare given the constraint of GATT Article XXIV. In stage 3, firms $I$ and $E$ simultaneously decide whether to comply with the ROO. In stage 4 , the two firms compete in country A's market in a Cournot fashion. As usual, we use backward induction to solve the game for the subgame perfect Nash equilibrium (SPNE). In the subsequent analysis, we focus on interior solutions.

The reason for assuming that the ROO are determined prior to the choice of country A's external tariff is as follows: the ROO are actually determined during the negotiations of the FTA among the negotiating countries. It should be set at the conclusion of the negotiation. In contrast, individual countries can change their own external tariffs even after the FTA comes into force as long as the change does not violate GATT Article XXIV. Therefore, it is quite natural to consider the case in which the ROO are set first and country A's external tariff is chosen later.

\section{Benchmark: Before an FTA is Formed}

We first analyze the equilibrium before countries A and B form an FTA. Profits of firms $I$ and $E$ are, respectively, given by

$$
\pi^{I}=(p-t-c) x, \quad \pi^{E}=(p-t) y .
$$

The outputs of firms $I$ and $E$ in a Nash equilibrium (NE) are, respectively, given by

$$
x_{b}=(a-t-2 c) / 3, \quad y_{b}=(a-t+c) / 3,
$$

where the subscript $b$ indicates equilibrium variables in the benchmark case. Profits of firms $I$ and $E$ in an NE are, respectively, given by

$$
\pi_{b}^{I}=\left(x_{b}\right)^{2}=(a-t-2 c)^{2} / 9, \quad \pi_{b}^{E}=\left(y_{b}\right)^{2}=(a-t+c)^{2} / 9 .
$$

Moreover, consumer surplus in country A is given by

$$
C S_{b}^{A}=\left(x_{b}+y_{b}\right)^{2} / 2=(2 a-2 t-c)^{2} / 18 .
$$

\footnotetext{
${ }^{5}$ An alternative version is that firm $E$ produces goods at a plant in country B. Initially, it uses intermediate inputs imported cheaply from country C. To comply with the ROO, however, firm $E$ needs to purchase a certain percentage of inputs from suppliers in country B. As firm $E$ has to make an arm's-length transaction with local suppliers, it incurs higher costs to comply with the ROO.
} 
Note that the case of $t=0$ in Eqs. (3) and (4) means that country A removes its tariff on imports, whereas it can also be interpreted as the case of an FTA between countries A and B without ROO. Thus, the following lemma is obtained from Eqs. (4) and (5):

Lemma 1. The formation of an FTA between countries $A$ and $B$ without ROO increases both firms' profits and country A's consumer surplus.

Country A sets a tariff to maximize its domestic welfare. Country A's domestic welfare before the formation of the FTA, $W_{b}^{A}$, consists of consumer surplus and tariff revenue:

$$
\begin{aligned}
W_{b}^{A} & =C S_{b}^{A}+t\left(x_{b}+y_{b}\right) \\
& =(2 a-2 t-c)^{2} / 18+t(2 a-2 t-c) / 3 .
\end{aligned}
$$

Thus, the following lemma is obtained:

Lemma 2. Prior to forming an FTA, the optimal tariff for country A is given by

$$
t_{b} \equiv(2 a-c) / 8
$$

Proof. Differentiating Eq. (6) with respect to $t$ yields $\mathrm{d} W_{b}^{A} / \mathrm{d} t=(2 a-c-8 t) / 9$. Solving $\mathrm{d} W_{b}^{A} / \mathrm{d} t=0$ for $t$, we obtain Eq. (7). The second-order condition is satisfied because $\mathrm{d}^{2} W_{b}^{A} / \mathrm{d} t^{2}=-8 / 9<0$.

Note that substitute $t=t_{b} \equiv(2 a-c) / 8$ into $x_{b}$ in Eq. (3) to yield

$$
x_{b}\left(t_{b}\right)=\left(a-t_{b}-2 c\right) / 3=(2 a-5 c) / 8 .
$$

Thus, we need to assume that

$$
a / c>5 / 2
$$

to ensure interior solutions.

\section{Effects of FTA with ROO}

Next, we examine the equilibrium of the game after countries A and B form an FTA with ROO. As there are four cases to be considered, we look at each case and then analyze the firms' equilibrium strategies. ${ }^{6}$

\footnotetext{
${ }^{6}$ In this paper's model setting, country A has no incentive to form an FTA with country B as far as the industry in question is concerned. However, we implicitly assume that there is another industry, outside the scope of this paper, in which country A gains from an FTA with country B.
} 


\subsection{Regime $C C$ : Both firms comply with the ROO}

We first consider the case in which both firms comply with the ROO. We call this case "regime $C C$." In this case, since both firms incur ROO compliance costs, profits of firms $I$ and $E$ are, respectively, given by

$$
\pi^{I}=(p-c-\phi) x, \quad \pi^{E}=(p-k \phi) y
$$

The outputs of firms $I$ and $E$ in the NE of stage 4 are, respectively, given by

$$
x_{c c}=(a-2 c+(k-2) \phi) / 3, \quad y_{c c}=(a+c-(2 k-1) \phi) / 3,
$$

where the subscript $c c$ indicates equilibrium variables in the case of both firms complying with the ROO (i.e., $c$ for "compliance"). Profits of firms $I$ and $E$ in the NE of stage 4 are, respectively, given by

$$
\pi_{c c}^{I}=\left(x_{c c}\right)^{2}=(a-2 c+(k-2) \phi)^{2} / 9, \quad \pi_{c c}^{E}=\left(y_{c c}\right)^{2}=(a+c-(2 k-1) \phi)^{2} / 9
$$

Thus, the following lemma emerges immediately:

Lemma 3. In regime $C C$, tightening the stringency of $R O O$ always decreases profits of firm $E$ and increases those of firm $I$ for $k>2$.

Proof. From Eq. (11), we differentiate each firm's profits with respect to $\phi$ to obtain

$$
\begin{aligned}
\frac{\partial \pi_{c c}^{E}}{\partial \phi} & =-\frac{2}{3}(2 k-1) y_{c c}<0 \\
\frac{\partial \pi_{c c}^{I}}{\partial \phi} & =\frac{2}{3}(k-2) x_{c c} .
\end{aligned}
$$

It follows that $\partial \pi_{c c}^{I} / \partial \phi>(<) 0 \Leftrightarrow k>(<) 2$.

Thus, when both firms comply with the ROO, if the compliance costs of the ROO are sufficiently larger for firm $E$ than for firm $I$, more stringent ROO can improve firm $I$ 's profits.

Moreover, consumer surplus in country $\mathrm{A}$ in regime $C C$ is given by

$$
C S_{c c}^{A}=\left(x_{c c}+y_{c c}\right)^{2} / 2=(2 a-c-(1+k) \phi)^{2} / 18
$$

Therefore, more stringent ROO always reduce $C S_{c c}^{A}$, which indicates an anti-competitive effect of ROO, as pointed out by Lopez-de-Silanes, Markusen, and Rutherford (1996).

\subsection{Regime $C N$ : Only firm $I$ complies with the ROO}

Next, we consider the case in which only firm $I$ complies with the ROO. We call this case "regime $C N$." Firms' profits in this case are given by

$$
\pi^{I}=(p-c-\phi) x, \quad \pi^{E}=(p-t) y .
$$


The outputs of firms $I$ and $E$ in the NE of stage 4 are, respectively, given by

$$
x_{c n}=(a-2(c+\phi)+t) / 3, \quad y_{c n}=(a+(c+\phi)-2 t) / 3,
$$

where the subscript $\mathrm{cn}$ indicates equilibrium variables in the case where firm $I$ complies with the ROO (i.e., $c$ for "compliance") and firm $E$ does not comply with the ROO (i.e., $n$ for "non-compliance"). Profits of firms $I$ and $E$ in the NE of stage 4 are, respectively, given by

$$
\pi_{c n}^{I}=\left(x_{c n}\right)^{2}=(a-2(c+\phi)+t)^{2} / 9, \quad \pi_{c n}^{E}=\left(y_{c n}\right)^{2}=(a+(c+\phi)-2 t)^{2} / 9
$$

From Eq. (15), the following lemma is immediately obtained:

Lemma 4. In regime $C N$, tightening the stringency of the ROO always increases the profits of firm $E$ and decreases those of firm $I$.

When only firm $I$ complies with the ROO, tightening ROO stringency increases compliance costs only for firm $I$. Firm $E$, which pays tariff $t$, is unaffected by the change in $\phi$. Thus, higher ROO stringency is damaging to firm $I$ and beneficial to firm $E$. This is the rent-shifting effect of the ROO (Lopez-de-Silanes, Markusen, and Rutherford, 1996).

Moreover, consumer surplus in country $\mathrm{A}$ in regime $C N$ is given by

$$
C S_{c n}^{A}=\left(x_{c n}+y_{c n}\right)^{2} / 2=(2 a-c-t-\phi)^{2} / 18
$$

As in regime $C C$, more stringent ROO always reduce $C S_{c n}^{A}$, even when only one firm complies with the ROO, due to the anti-competitive effect of ROO (Lopez-de-Silanes, Markusen, and Rutherford, 1996).

\subsection{Regime $N C$ : Only firm $E$ complies with the ROO}

In the third case, only firm $E$ complies with the ROO, which is "regime $N C$." Firms' profits in this case are given by

$$
\pi^{I}=(p-c-t) x, \quad \pi^{E}=(p-k \phi) y
$$

Then, the outputs and profits of firms $I$ and $E$ in the NE of stage 4 are, respectively, given by

$$
\begin{array}{lll}
x_{n c}=(a-2(c+t)+k \phi) / 3, & y_{n c}=(a+c+t-2 k \phi) / 3, \\
\pi_{n c}^{I}=\left(x_{n c}\right)^{2}=(a-2(c+t)+k \phi)^{2} / 9, & \pi_{n c}^{E}=\left(y_{n c}\right)^{2}=(a+c+t-2 k \phi)^{2} / 9,
\end{array}
$$

where the subscript $n c$ indicates equilibrium variables in the case where firm $I$ does not comply with the ROO and firm $E$ does. 


\subsection{Regime $N N$ : Neither firm complies with the ROO}

Finally, if compliance costs are too high, neither firm complies with the ROO. We call this case "regime $N N$." In this case, both firms supply goods to country A's market by paying A's external tariff $t$. Thus, this case corresponds to the benchmark case in Section 3.

\subsection{Firms' equilibrium strategies}

Based on the above results, we analyze the equilibrium in the third stage. In the third stage, firms simultaneously decide whether to comply with the ROO. We assume a small fixed cost $\varepsilon>0$ for compliance with the ROO, so that if gross profits are the same for compliance and non-compliance, a firm chooses non-compliance. ${ }^{7}$ Then, it is found that the equilibrium is determined by the range of the stringency of the ROO $\phi$. We obtain the following proposition:

Proposition 1. The equilibrium in stage 3 is as follows: (i) Both firms comply with the ROO (i.e., regime $C C$ ) for $0 \leq \phi<t / k$; (ii) Only firm I complies with the ROO (i.e., regime $C N$ ) for $t / k \leq \phi<$ t; and (iii) Neither firm complies with the ROO, and both firms supply goods to country A's market by paying tariffs $t$ (i.e., regime $N N$ ) for $t \leq \phi$.

Proof. See Appendix A.

Therefore, firms decide whether to comply with the ROO depending on the relative magnitudes of ROO stringency and country A's tariff level. For a given level of ROO, firms have a higher incentive to comply as country A's tariff increases.

\section{Optimal ROO, External Tariff, and Welfare of the FTA Members}

In this section, we analyze the choice of country A's external tariff in the second stage of the game and the optimal ROO set by the FTA members in the first stage of the game.

Joint welfare of the FTA members comprises the sum of consumer surplus in country A, the tariff revenue of country A, and firm I's profits:

$$
W^{A B}=C S^{A}+\pi^{I}+t \times z
$$

where $z$ is the amount of exports to country A that do not satisfy the ROO, i.e.,

$$
z= \begin{cases}0, & \text { in regime } C C, \\ y_{c n}, & \text { in regime } C N, \text { and } \\ x_{b}+y_{b}, & \text { in regime } N N .\end{cases}
$$

\footnotetext{
${ }^{7}$ In the subsequent analysis of welfare, we exclude $\varepsilon$ to simplify calculations.
} 
Note that in stage 2, country A sets the optimal external tariff under the condition of paragraph 4 of GATT Article XXIV that trade barriers should not be raised against non-members of an FTA after the FTA is formed.

\subsection{Regime $N N$ : Neither firm complies with the ROO}

We first consider the case in which neither firm complies with the ROO (i.e., regime $N N$ ). In this case, both firms supply goods to the market in country A by paying the tariff imposed by country A. As the equilibrium in stages 3 and 4 is the same as that before the FTA is formed, the optimal tariff set by country A in stage 2 should also be the same as that prior to forming the FTA, which is $t=t_{b}=(2 a-c) / 8$ (Eq. (7)).

Joint welfare of the FTA members, in this case, is the sum of country A's welfare in the benchmark case shown in Section 3 and firm I's profits. Thus, from Eqs. (6) and (4), we obtain

$$
\begin{aligned}
W_{n n}^{A B} & =C S_{b}^{A}+\pi_{b}^{I}+t\left(x_{b}+y_{b}\right) \\
& =\frac{(2 a-2 t-c)^{2}}{18}+\frac{(a-t-2 c)^{2}}{9}+t \frac{(2 a-2 t-c)}{3} \\
& =\frac{1}{6}\left(2 a^{2}-4 a c+3 c^{2}-2 t^{2}+2 c t\right) .
\end{aligned}
$$

From Proposition 1, the game reaches this case if the ROO satisfy $t \leq \phi$. Thus, in stage 1 , any $\phi$ that satisfies $\phi \geq t_{b}=(2 a-c) / 8$ is the optimal ROO in this case.

Substituting Eq. (7) into Eq. (19), we obtain

$$
W_{n n}^{A B}\left(t_{b}\right)=\frac{5}{16} a^{2}-\frac{9}{16} a c+\frac{29}{64} c^{2} .
$$

Since no change occurs for the welfare of either country A or country B by forming the FTA, neither country benefits from the formation.

\subsection{Regime $C N$ : Only firm $I$ complies with the ROO}

Next, we consider the case in which only firm $I$ complies with the ROO (i.e., regime $C N$ ). Country A sets the optimal tariff $t$ to maximize its domestic welfare. From Eqs. (14) and (16), welfare of country $\mathrm{A}$ in this case is given by

$$
\begin{aligned}
W_{c n}^{A} & =C S_{c n}^{A}+t y_{c n} \\
& =\frac{(2 a-c-t-\phi)^{2}}{18}+t \frac{(a+(c+\phi)-2 t)}{3} \\
& =\frac{1}{18}\left[-11 t^{2}+2(a+4 c+4 \phi) t+(2 a-c-\phi)^{2}\right] .
\end{aligned}
$$

From the first-order condition for welfare maximization, the optimal tariff for country A in stage 2 is given by

$$
t_{c n}(\phi)=(a+4 c+4 \phi) / 11
$$


Then, we examine the optimal ROO in stage 1. Joint welfare of countries A and B in this case is obtained by substituting Eqs. (14), (15), and (16) into Eq. (18):

$$
\begin{aligned}
W_{c n}^{A B} & =C S_{c n}^{A}+\pi_{c n}^{I}+t y_{c n} \\
& =\frac{(2 a-c-t-\phi)^{2}}{18}+\frac{(a-2(c+\phi)+t)^{2}}{9}+t \frac{(a+(c+\phi)-2 t)}{3} .
\end{aligned}
$$

Moreover, substituting Eq. (22) into Eq. (23) yields

$$
W_{c n}^{A B}=\frac{1}{242}\left[105 \phi^{2}-70(2 a-3 c) \phi+\left(87 a^{2}-140 a c+105 c^{2}\right)\right] .
$$

Eq. (24) indicates that $W_{c n}^{A B}$ is a quadratic function in $\phi$, with a positive coefficient for the $\phi^{2}$ term, which means that the $W_{c n}^{A B}$ curve is concave up. In addition, since we have

$$
\frac{\partial W_{c n}^{A B}}{\partial \phi}=\frac{1}{242}[210 \phi-70(2 a-3 c)]
$$

$W_{c n}^{A B}$ reaches the minimum at $\phi=\phi_{1} \equiv(2 a-3 c) / 3>0$.

From Proposition 1, regime $C N$ arises when the ROO and country A's tariff satisfy $t / k \leq \phi<t$. Then, depending on the relative magnitudes of $\phi_{1}, t / k$, and $t$, there are three possible cases. However, in any case, the optimal ROO in stage 1 in this regime, $\phi_{c n}$, is given by a corner solution. That is, either $\phi_{c n}=t / k$ or $\phi_{c n}=t$ is the possible solution. We examine the two cases in order.

First, consider the case of $\phi_{c n}=t$. From Eq. (22), solving $\phi=t=(a+4 c+4 \phi) / 11$ for $\phi$ yields

$$
\phi_{c n 1} \equiv(a+4 c) / 7
$$

Then, joint welfare of the FTA members is obtained by substituting Eq. (25) into Eq. (24):

$$
W_{c n}^{A B}\left(\phi_{c n 1}\right)=\frac{2}{7} a^{2}-\frac{5}{7} a c+\frac{15}{14} c^{2} .
$$

Note that if $t_{c n}\left(\phi_{c n 1}\right)$ is greater than the pre-FTA optimal tariff, $t_{b}, t_{c n}\left(\phi_{c n 1}\right)$ cannot be chosen; hence, the tariff set by country $\mathrm{A}$ in stage 2 is $t=t_{b}=(2 a-c) / 8$. If that is the case, the ROO are also $\phi_{b} \equiv(2 a-c) / 8=t_{b}$. The condition for this case is obtained by solving $(a+4 c) / 7>(2 a-c) / 8$ and defining $\alpha \equiv a / c$, which is $\alpha<13 / 2$. Joint welfare of the FTA members in this case is given by substituting $t=t_{b}=(2 a-c) / 8$ and $\phi=\phi_{b}=(2 a-c) / 8$ into Eq. $(23)$ :

$$
W_{c n}^{A B}\left(\phi_{b}\right)=\frac{1}{8}\left(2 a^{2}-3 a c+3 c^{2}\right)
$$

Next, consider the case of $\phi_{c n}=t / k$. Similar to the previous case, from Eq. (22), solving $\phi=t / k=(a+4 c+4 \phi) / 11 k$ for $\phi$, we obtain

$$
\phi_{c n 2} \equiv(a+4 c) /(11 k-4)
$$

Substituting Eq. (28) into Eq. (22) yields

$$
t_{c n}\left(\phi_{c n 2}\right)=(a+4 c) k /(11 k-4)
$$


Joint welfare of countries A and B is obtained by substituting Eq. (28) into Eq. (24):

$$
W_{c n}^{A B}\left(\phi_{c n 2}\right)=\frac{\left(87 a^{2}-140 a c+105 c^{2}\right) k^{2}-2 a(38 a-35 c) k+17 a^{2}}{2(11 k-4)^{2}} .
$$

As in the previous case, if $t_{c n}\left(\phi_{c n 2}\right)>t_{b}$, then $t=t_{b}$ is chosen; hence, $\phi=\phi_{b} / k=(2 a-c) / 8 k=t_{b} / k$ holds. Thus, joint welfare of the FTA members is given by substituting $t=t_{b}=(2 a-c) / 8$ and $\phi=\phi_{b} / k=(2 a-c) / 8 k=t_{b} / k$ into Eq. $(23)$ :

$$
W_{c n}^{A B}\left(\phi_{b} / k\right)=\frac{1}{384 k^{2}}\left\{\left(148 a^{2}-260 a c+189 c^{2}\right) k^{2}-16(2 a-c)(2 a-3 c) k+3(2 a-c)^{2}\right\} .
$$

The condition for this case to hold is obtained as follows. From $t_{c n}\left(\phi_{c n 2}\right)=(a+4 c) k /(11 k-4)>$ $(2 a-c) / 8=t_{b}$ and using $\alpha \equiv a / c$, we have $k<4(2 \alpha-1) /(14 \alpha-43)$. Then, from (8), and noting $\alpha>5 / 2$, as $4(2 \alpha-1) /(14 \alpha-43)<0$ holds for $\alpha<43 / 14$ and $4(2 \alpha-1) /(14 \alpha-43)<1$ holds for $\alpha>13 / 2$, the condition can be satisfied only in the range of $43 / 14<\alpha<13 / 2$. Thus, only if both $43 / 14<\alpha<13 / 2$ and $k<4(2 \alpha-1) /(14 \alpha-43)$ are satisfied, $\phi_{c n}=\phi_{b} / k=(2 a-c) / 8 k$. Otherwise, $\phi_{c n}=\phi_{c n 2}$.

As shown above, in regime $C N$, the possible combinations of the policies set in the first and second stages of the game are $\left(\phi_{c n}, t_{c n}\right)=\left\{\left(\phi_{c n 1}, t_{c n}\left(\phi_{c n 1}\right)\right),\left(\phi_{b}, t_{b}\right),\left(\phi_{c n 2}, t_{c n}\left(\phi_{c n 2}\right)\right),\left(\phi_{b} / k, t_{b}\right)\right\}$. Then, the following lemma specifies the optimal ROO in this regime:

Lemma 5. Assume that $\alpha \equiv a / c>5 / 2$. Then, optimal $R O O$ in regime $C N \phi_{c n}$ is as follows:

(i) For $5 / 2<\alpha \leq 43 / 14 \approx 3.07$, if

$$
k<\frac{4(2 \alpha-3)(8 \alpha+11)+2(\alpha+4) \sqrt{35(2 \alpha-3)(\alpha-3)}}{(2 \alpha-3)(53 \alpha-19)}
$$

holds, then $\phi_{c n}=\phi_{b}=(2 a-c) / 8$. Otherwise, $\phi_{c n}=\phi_{c n 2}=(a+4 c) /(11 k-4)$.

(ii) For $43 / 14<\alpha$, if

$$
k<\frac{4(2 \alpha-1)}{(14 \alpha-43)}
$$

then $\phi_{c n}=\phi_{b} / k=(2 a-c) / 8 k$, and if

$$
k \geq \frac{4(2 \alpha-1)}{(14 \alpha-43)}
$$

holds, then $\phi_{c n}=\phi_{c n 2}=(a+4 c) /(11 k-4)$.

Proof. See Appendix B.

Figure 1 indicates the optimal ROO in regime $C N$ shown in Lemma 5 in the plane of $(\alpha, k)$. In this figure, $\alpha$ is taken on the horizontal axis, and $k$ is taken on the vertical axis. Since we assume that $\alpha>5 / 2$ and $k>1$, the horizontal axis starts from $\alpha=2.5$, and the vertical axis starts from $k=1$. The quadrant is divided into four segments by an upward-sloping curve corresponding to (32) with 


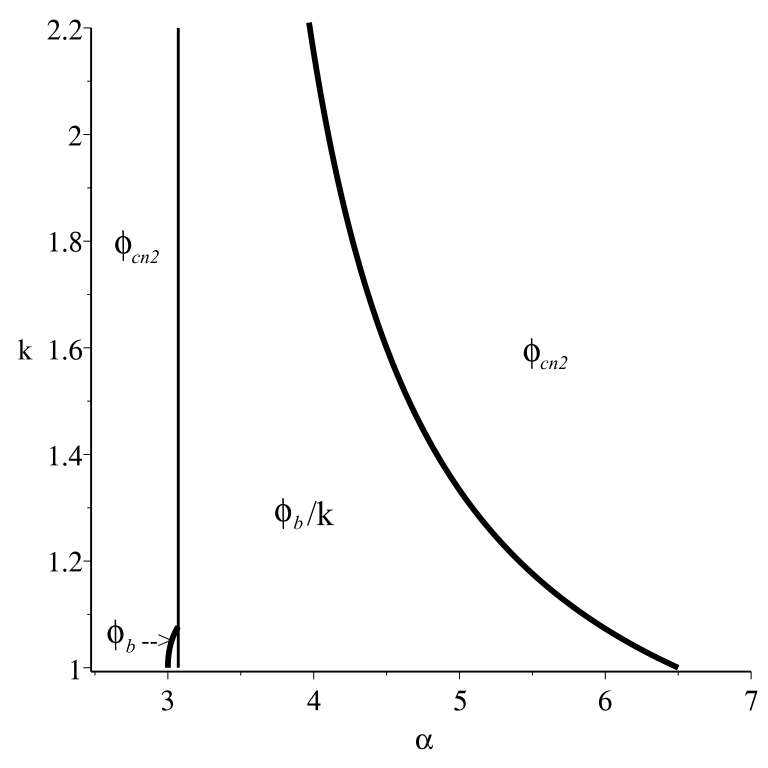

Figure 1: Optimal ROO in regime $C N$

equality, a vertical line at $\alpha=43 / 14 \approx 3.07$, and a downward-sloping curve corresponding to (33) with equality.

As is indicated in the figure, the optimal ROO is $\phi_{c n}=\phi_{c n 2}=(a+4 c) /(11 k-4)$ in the segments left of the $\alpha=43 / 14$ line and right of the downward-sloping curve. It is $\phi_{c n}=\phi_{b} / k=(2 a-c) / 8 k$ in the middle segment. Finally, $\phi_{c n}=\phi_{b}=(2 a-c) / 8$ is optimal in a small segment around $\alpha=3$ and $k=1.05$.

\subsection{Regime $C C$ : Both firms comply with the ROO}

Finally, we consider the case in which both firms comply with the ROO (i.e., regime $C C$ ). From Proposition 1, this case arises when $0 \leq \phi<t / k$. Thus, in stage 2 , any $t$ that satisfies $t>k \phi$ is optimal. In this case, since neither firm pays the tariff, joint welfare of the members only comprises consumer surplus in country A and firm I's profits. Substituting Eqs. (11) and (12) into Eq. (18) yields

$$
\begin{aligned}
W_{c c}^{A B} & =C S_{c c}^{A}+\pi_{c c}^{I} \\
& =\frac{(2 a-c-(1+k) \phi)^{2}}{18}+\frac{(a-2 c+(k-2) \phi)^{2}}{9} \\
& =\frac{1}{18}\left[3\left(k^{2}-2 k+3\right) \phi^{2}-6(2 a-3 c+c k) \phi+3\left(2 a^{2}-4 a c+3 c^{2}\right)\right] .
\end{aligned}
$$

Then, we consider the optimal level of ROO in this case. First, in the previous section, we show that for $k \leq 2$, consumer surplus in country A and firm I's profits are both decreasing in $\phi$. Thus, 
the optimal ROO for $k \leq 2$ is $\phi=0$.

Next, we examine the case of $k>2$. Eq. (35) indicates that $W_{c c}^{A B}$ is a quadratic function in $\phi$ with the coefficient of the $\phi^{2}$ term being positive for $k>2$, implying that the $W_{c c}^{A B}$ curve is concave up. In addition, $\partial W_{c c}^{A B} / \partial \phi=0$ yields

$$
\phi=\phi_{2} \equiv \frac{2 a-3 c+c k}{k^{2}-2 k+3}>0 .
$$

Thus, $W_{c c}^{A B}$ reaches the minimum at $\phi=\phi_{2}$.

From Proposition 1, the optimal ROO in this case must satisfy $0 \leq \phi<t / k$. Thus, depending on the relative magnitudes of $\phi_{2}$ and $t / k$, there are two possible cases; however, in either case, the optimal ROO $\phi_{c c}$ must be given by a corner solution. That is, either $\phi_{c c}=0$ or $\phi_{c n}=t / k$. For $\phi_{c n}=t / k$, each firm's profits and the consumer surplus in country A must be the same as those in the case where only firm $I$ complies with the ROO, i.e., $\pi_{c n}^{I}, \pi_{c n}^{E}$ and $C S_{c n}^{A}$. Though country A earns tariff revenue in the case where only firm $I$ complies with the ROO, no tariff revenue is available in the case of compliance by both firms. Thus, joint welfare of the FTA members in the latter case cannot be greater than that in the former case with the optimal policies. Therefore, we only need to consider $\phi_{c c}=0$ as the candidate of the optimal ROO in the case of both firms complying with the ROO. The following lemma is then obtained:

Lemma 6. In regime $C C$, regardless of the level of $k$, we only need to consider $\phi_{c c}=0$ as the candidate for the optimal ROO. Joint welfare of countries $A$ and $B$ attained by $\phi_{c c}=0$ is as follows:

$$
W_{c c}^{A B}\left(\phi_{c c}=0\right)=\frac{1}{6}\left(2 a^{2}-4 a c+3 c^{2}\right) .
$$

\subsection{Optimal ROO, external tariff, and firms' strategies}

Now, we solve the model for the optimal ROO, country A's optimal external tariff, and firms' strategies in the SPNE of the four-stage game.

From the analysis above, we know the optimal ROO in each regime. Thus, we only need to determine the regime in which the joint welfare of the FTA members is maximized. As shown below, it depends on the parameter values. We find that the equilibrium regime can be specified by two parameters: $\alpha \equiv a / c$ and $k$. On the one hand, $\alpha$ is the ratio of the "market size" of country A's market to the relative cost disadvantage of firm $I$. A small value of $\alpha$ indicates that the cost difference between firm $I$ and firm $E$ is relatively large when the measurement is weighted by country A's market size. In other words, firm $I$ 's marginal cost is considerably higher than that of firm $E$ (as weighted by country A's market size). A large value of $\alpha$ indicates that the cost difference between the two firms is relatively small. On the other hand, $k$ measures the difference in compliance costs of the ROO between the two firms. A value of $k$ close to one indicates that the additional compliance costs for 
firm $E$ relative to firm $I$ are small. A large value of $k$ indicates that firm $E$ has to incur much higher compliance costs for satisfying the ROO than firm $I$.

First, we compare joint welfare of countries A and B in regimes $N N$ and $C C$. From Eqs. (20) and (36), we obtain

$$
W_{n n}^{A B}\left(t_{b}\right)-W_{c c}^{A B}\left(\phi_{c c}=0\right)=-\frac{c^{2}(2 \alpha-1)(2 \alpha-9)}{192} .
$$

Thus, given that we assume $\alpha>5 / 2$ (see Eq. (8)), if $5 / 2<\alpha \leq 9 / 2$, then $W_{n n}^{A B}\left(t_{b}\right) \geq W_{c c}^{A B}\left(\phi_{c c}=0\right.$ ) holds, and if $\alpha>9 / 2$, then $W_{n n}^{A B}\left(t_{b}\right)<W_{c c}^{A B}\left(\phi_{c c}=0\right)$ holds. This means that for $5 / 2<\alpha \leq 9 / 2$, we need to further compare joint welfare of countries $\mathrm{A}$ and $\mathrm{B}$ in regimes $C N$ and $N N$ and that, for $\alpha>9 / 2$, we need to compare the joint welfare of the FTA members in regimes $C N$ and $C C$.

In the range of $5 / 2<\alpha \leq 9 / 2$, it is found that it is convenient to divide the range into $5 / 2<$ $\alpha \leq(953+44 \sqrt{205}) / 546 \approx 2.90$ and $(953+44 \sqrt{205}) / 546<\alpha \leq 9 / 2$. Then, the optimal policies and firms' strategies in SPNE are shown in the following proposition.

Proposition 2. Assume $\alpha>5 / 2$. Let $\phi^{*}$ and $t^{*}$ be the optimal ROO in stage 1 and country A's optimal external tariff in stage 2 in SPNE, respectively. Then, the following is the SPNE of the fourstage game:

(i) For $5 / 2<\alpha \leq 43 / 14$, if $(\alpha, k)$ satisfies

$$
\begin{aligned}
& \frac{4\left\{84 \alpha^{2}+116 \alpha-319-(\alpha+4) \sqrt{70\left(28 \alpha^{2}-108 \alpha+87\right)}\right\}}{364 \alpha^{2}-124 \alpha-149}<k \\
& <\frac{4\left\{84 \alpha^{2}+116 \alpha-319+(\alpha+4) \sqrt{70\left(28 \alpha^{2}-108 \alpha+87\right)}\right\}}{364 \alpha^{2}-124 \alpha-149},
\end{aligned}
$$

then $\phi^{*}=\{\phi \mid \phi>(2 a-c) / 8\}$ and $t^{*}=t_{b}=(2 a-c) / 8$ (Eq. (7)). (37) can be satisfied only for $\alpha>(27+2 \sqrt{30}) / 14 \approx 2.71$. The equilibrium regime is $N N$. Otherwise, $\phi^{*}=\phi_{c n 2}=(a+4 c) /(11 k-4)$ (Eq. (29)) and $t^{*}=t_{c n}\left(\phi_{c n 2}\right)=(a+4 c) k /(11 k-4)$ (Eq. (29)). The equilibrium regime is $C N$.

(ii) For $43 / 14<\alpha \leq 9 / 2$, if $(\alpha, k)$ satisfies (33) and

$$
k \geq \frac{8(2 \alpha-3)+\sqrt{172 \alpha^{2}-636 \alpha+531}}{14 \alpha-15},
$$

then $\phi^{*}=\phi_{b} / k=(2 a-c) / 8 k$ and $t^{*}=t_{b}=(2 a-c) / 8(E q .(7))$. Firms choose regime $C N$. If $(\alpha, k)$ satisfies (34) and

$$
k \geq \frac{4\left\{84 \alpha^{2}+116 \alpha-319+(\alpha+4) \sqrt{70\left(28 \alpha^{2}-108 \alpha+87\right)}\right\}}{364 \alpha^{2}-124 \alpha-149},
$$

then $\phi^{*}=\phi_{c n 2}=(a+4 c) /(11 k-4)\left(E q\right.$. (29)) and $t^{*}=t_{c n}\left(\phi_{c n 2}\right)=(a+4 c) k /(11 k-4)(E q$. (29)). The equilibrium regime is $C N$. Otherwise, $\phi^{*}=\{\phi \mid \phi>(2 a-c) / 8\}$ and $t^{*}=t_{b}=(2 a-c) / 8(E q$. (7)). The equilibrium regime is $N N$.

(iii) For $\alpha>9 / 2$, if $(\alpha, k)$ satisfies

$$
k \geq \frac{26 \alpha-33+3 \sqrt{35 \alpha^{2}-140 \alpha+105}}{19 \alpha-12},
$$




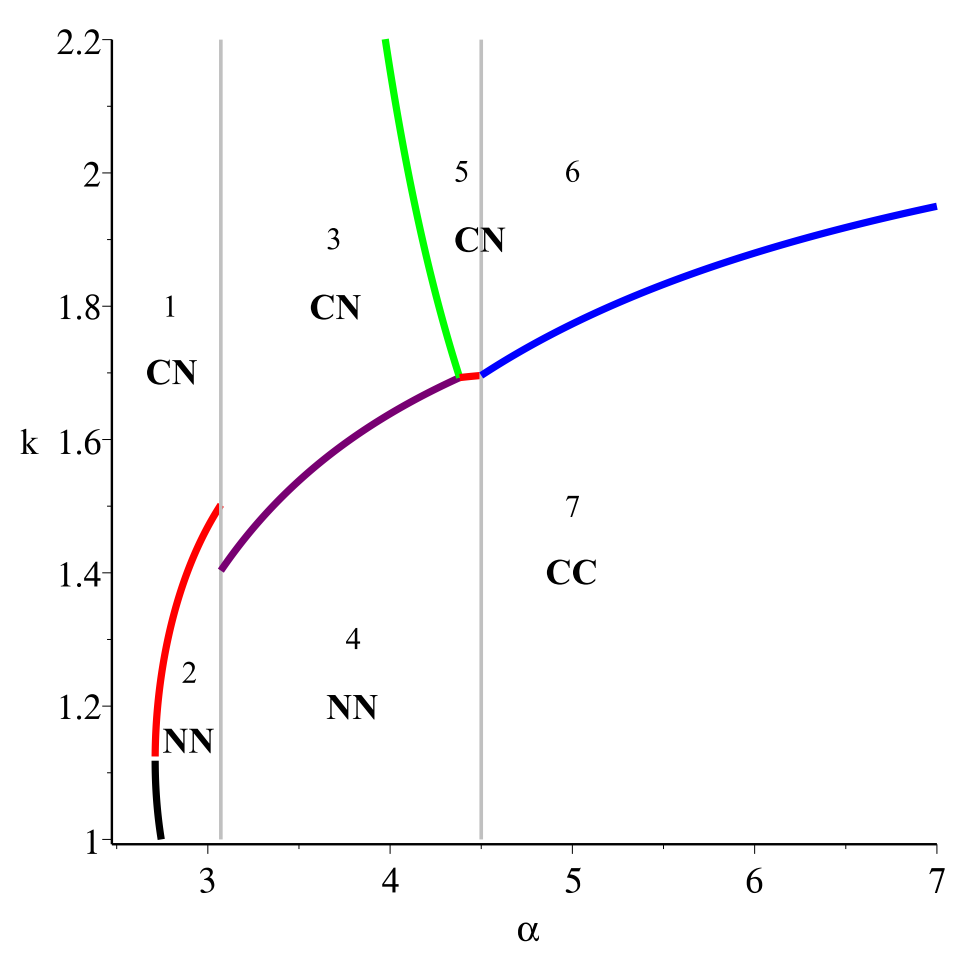

Figure 2: Optimal ROO and the equilibrium regime

then $\phi^{*}=\phi_{c n 2}=(a+4 c) /(11 k-4)\left(E q\right.$. (29)) and $t^{*}=t_{c n}\left(\phi_{c n 2}\right)=(a+4 c) k /(11 k-4)$ (Eq. (29)). The equilibrium regime is $C N$. Otherwise, $\phi^{*}=0$ and $t^{*}=\{t \mid t>0\}$. The equilibrium regime is $C C$.

Proof. See Appendix C.

As shown in the above proposition, when $\alpha$ is small (i.e., $\alpha \leq(27+2 \sqrt{30}) / 14$ ), which means that the difference in marginal production costs between the two firms is sufficiently large, the ROO that induce firm $I$ to comply and firm $E$ not to comply are optimal regardless of the value of $k$. For medium values of $\alpha$ (i.e., $(27+2 \sqrt{30}) / 14<\alpha \leq 9 / 2$ ), if $k$ is relatively small (i.e., the degree of disadvantage of firm $E$ in compliance costs is relatively low), the ROO that induces both firms not to comply are optimal; if $k$ is relatively large (i.e., the degree of disadvantage of firm $E$ in compliance costs is relatively high), the ROO that induce firm $I$ to comply and firm $E$ not to comply are optimal. Finally, when $\alpha$ is large (i.e., $\alpha>9 / 2$ ), which means that the cost difference between the two firms is sufficiently small, then if $k$ is relatively large, the ROO that induce both firms to comply are optimal, and if $k$ is relatively large, the ROO that induce firm $I$ to comply and firm $E$ not to comply are optimal.

The optimal ROO and equilibrium regime can be illustrated in the plane of $(\alpha, k)$ (see Figure 2). 
The two axes in Figure 2 are the same as those in Figure 1. In Figure 2, the following five equations are used to segment cases:

$$
\begin{aligned}
(N N 1): k & =\frac{4\left\{84 \alpha^{2}+116 \alpha-319+(\alpha+4) \sqrt{70\left(28 \alpha^{2}-108 \alpha+87\right)}\right\}}{364 \alpha^{2}-124 \alpha-149} \\
(N N 2): k & =\frac{4\left\{84 \alpha^{2}+116 \alpha-319-(\alpha+4) \sqrt{70\left(28 \alpha^{2}-108 \alpha+87\right)}\right\}}{364 \alpha^{2}-124 \alpha-149} \\
(N N 3): k & =\frac{8(2 \alpha-3)+\sqrt{172 \alpha^{2}-636 \alpha+531}}{14 \alpha-15} \\
(C N): k & =\frac{4(2 \alpha-1)}{(14 \alpha-43)} \\
(C C): k & =\frac{26 \alpha-33+3 \sqrt{35 \alpha^{2}-140 \alpha+105}}{19 \alpha-12}
\end{aligned}
$$

The NN1 curves are upward-sloping red curves, which appear twice in the figure. The NN2 curve is a downward-sloping black curve, and the NN3 curve is an upward-sloping purple curve. The $C N$ curve is a downward-sloping green curve, and the $C C$ curve is an upward-sloping blue curve. Moreover, two vertical lines are drawn at $\alpha=43 / 14 \approx 3.07$ and $\alpha=9 / 2$.

As indicated in Figure 2, the equilibrium regime is $C N$ in segments 1, 3, 5, and 6; $N N$ in segments 2 and 4 ; and $C C$ in segment 7. In regime $C N$, the optimal ROO and country A's optimal tariff are $\phi^{*}=\phi_{c n 2}$ and $t^{*}=t_{c n}\left(\phi_{c n 2}\right)$, respectively, in segments 1,5 , and 6 and $\phi^{*}=\phi_{b} / k$ and $t^{*}=t_{b}$, respectively, in segment 3. In other regimes, the optimal policies are $\phi^{*}=\{\phi \mid \phi>(2 a-c) / 8\}$ and $t^{*}=t_{b}$ in segment 4 (i.e., regime $N N$ ) and $\phi^{*}=0$ and $t^{*}=\{t \mid t>0\}$ in segment 7 (i.e., regime $C C$ ).

The results in Proposition 2 can be explained as follows. In regime $C N$, compliance costs paid by firm $I$ are simply a loss with regard to welfare of the FTA members. Nevertheless, if $\alpha$ is sufficiently small or $k$ is sufficiently high, regime $C N$ dominates the other two regimes. Intuitively, when $\alpha$ is sufficiently small, firm I's market share is very small; hence, the loss is also small. On the other hand, when $k$ is sufficiently high, the optimal ROO in regime $C N$ becomes less stringent because, for both $\phi^{*}=\phi_{c n 2}$ and $\phi^{*}=\phi_{b} / k$, the optimal ROO is given by the level of tariff divided by $k$. Thus, a higher $k$ makes firm $I$ 's compliance costs smaller and the relative trade barrier for firm $I$ lower. ${ }^{8}$ However, these explanations are not enough for understanding the results in Proposition 2. In fact, the mechanism for the FTA members' welfare to be higher in regime $C N$ is different, depending on whether a comparison is made with regime $N N$ or regime $C C$. First, in regime $N N$, both firms face the same trade barrier $t_{b}$. By changing the regime to $C N$ with $\phi^{*}=\phi_{b} / k$ (i.e., segment 3 in Figure 2 ), the trade barrier to firm $I$ is reduced to $\phi_{b} / k=t_{b} / k$, keeping the trade barrier to firm $E$ at $t_{b}$.

\footnotetext{
${ }^{8}$ Here, the trade barrier for firm $I$ is given by $\phi$ and that for firm $E$ is given by $t$.
} 
This improves firm I's profits and consumer surplus in country A because

$$
\begin{aligned}
\pi_{c n}^{I}\left(\phi_{b} / k\right)-\pi_{n n}^{I}\left(t_{b}\right) & =\frac{\{(10 a-17 c) k-2(2 a-c)\}^{2}}{576 k^{2}}-\frac{(2 a-5 c)^{2}}{64} \\
& =\frac{c^{2}(k-1)(2 \alpha-1)\{8(\alpha-2) k-(2 \alpha-1)\}}{144 k^{2}}>0 \quad \text { for } \alpha>5 / 2, \\
C S_{c n}^{A}\left(\phi_{b} / k\right)-C S_{n n}^{A}\left(t_{b}\right) & =\frac{(7 k-1)^{2}(2 a-c)^{2}}{1152 k^{2}}-\frac{(2 a-c)^{2}}{32} \\
& =\frac{(2 a-c)^{2}(k-1)(13 k-1)}{1152 k^{2}}>0 .
\end{aligned}
$$

Thus, contrary to the argument by Lopez-de-Silanes, Markusen, and Rutherford (1996), ROO have a rent-shifting effect from non-complier (i.e., firm $E$ ) to complier (i.e., firm $I$ ) and also a pro-competitive effect in this case. The reason is that ROO work as a discriminatory trade barrier, which allows FTA members to liberalize trade only for members, even if firm $E$ could potentially be eligible for tariff-free exports by complying with the ROO. As the gains in firm I's profits and consumer surplus exceed the loss of tariff revenue for firm $I$, in this case, welfare of the FTA members becomes higher in regime $C N$.

The reason why a change from regime $N N$ to regime $C N$ with $\phi^{*}=\phi_{c n 2}$ can improve welfare of the FTA members is similar to the previous case, but it is slightly complex. Compared with regime $N N$, trade barriers are reduced for both firms in regime $C N$ with $\phi^{*}=\phi_{c n 2}$, with a larger reduction for firm $I$. Since the market share of the inefficient firm (i.e., firm $I$ ) increases and that of the efficient firm (i.e., firm $E$ ) decreases, consumer surplus may increase or decrease, and even firm $I$ 's profits may increase or decrease. We have

$$
\begin{aligned}
C S_{c n}^{A}\left(\phi_{c n 2}\right)-C S_{n n}^{A}\left(t_{b}\right) & =\frac{\{(7 a-5 c) k-3 a\}^{2}}{2(11 k-4)^{2}}-\frac{(2 a-c)^{2}}{32} \\
& =\frac{c^{2}\{3(2 \alpha-3) k-4(\alpha+1)\}\{(50 \alpha-31) k-4(5 a-1)\}}{32(11 k-4)^{2}},
\end{aligned}
$$

where the terms within the second pair of curly bracket is positive for $\alpha>5 / 2$ but those within the first pair of curly brackets may be negative for a small $k$. With regard to firm $I$ 's profits, we have

$$
\begin{aligned}
\pi_{c n}^{I}\left(\phi_{c n 2}\right)-\pi_{n n}^{I}\left(t_{b}\right) & =\frac{4\{(2 a-3 c) k-a\}^{2}}{(11 k-4)^{2}}-\frac{(2 a-5 c)^{2}}{64} \\
& =\frac{c^{2}\{(54 \alpha-103) k-4(6 \alpha-5)\}\{(10 \alpha+7) k-4(2 \alpha+5)\}}{64(11 k-4)^{2}}
\end{aligned}
$$

which indicates that the sign depends on the size of $k$ and $\alpha$, though $\pi_{c n}^{I}\left(\phi_{c n 2}\right)>\pi_{n n}^{I}\left(t_{b}\right)$ holds whenever regime $C N$ dominates regime $N N$. Thus, in the domain of $\alpha \leq 43 / 14$, for small $k$, gain in firm I's profits due to a change from regime $N N$ to regime $C N$ alone exceeds the loss in consumer surplus and loss of tariff revenue from firm $I$.

In contrast, the mechanism for welfare of the FTA members to be higher in regime $C N$ than in regime $C C$ is explained by the following double rent-shifting. In regime $C C$, as the optimal ROO is 
$\phi_{c c}=0$, neither firm faces a trade barrier. From the perspective of the FTA members, though there is no tariff revenue, consumer surplus attains the highest level. By changing the regime from $C C$ to $C N$ with $\phi^{*}=\phi_{c n 2}$, consumer surplus must decrease. This can be checked by

$$
\begin{aligned}
C S_{c n}^{A}\left(\phi_{c n 2}\right)-C S_{c c}^{A}\left(\phi_{c c}=0\right) & =\frac{\{(7 a-5 c) k-3 a\}^{2}}{2(11 k-4)^{2}}-\frac{(2 a-c)^{2}}{18} \\
& =-\frac{c^{2}(k+1)(\alpha+4)\{(43 \alpha-26) k-(17 \alpha-4)\}}{18(11 k-4)^{2}}<0,
\end{aligned}
$$

which holds because $(17 \alpha-4) /(43 \alpha-26)<29 / 67 \approx 0.4333$ for $\alpha>9 / 2$. Firm I's profits are

$$
\begin{aligned}
\pi_{c n}^{I}\left(\phi_{c n 2}\right)-\pi_{c c}^{I}\left(\phi_{c c}=0\right) & =\frac{4\{(2 a-3 c) k-a\}^{2}}{(11 k-4)^{2}}-\frac{(a-c)^{2}}{9} \\
& =\frac{c^{2}(k-2)(\alpha+4)\{(23 \alpha-40) k-2(5 \alpha-4)\}}{9(11 k-4)^{2}} .
\end{aligned}
$$

Since $2(5 \alpha-4) /(23 \alpha-40)<74 / 127 \approx 0.583$ for $\alpha>9 / 2$, it holds that $\pi_{c n}^{I}\left(\phi_{c n 2}\right)>\pi_{c c}^{I}\left(\phi_{c c}=0\right)$ if and only if $k>2$. This is consistent with Lemma 3 . In regime $C N$ with $\phi^{*}=\phi_{c n 2}$, the two firms face discriminatory trade barriers, where the tariff that firm $E$ pays is higher by $k$ than the compliance costs of the ROO that firm $I$ incurs. For $k<2$, in spite of losses in both firm $I$ 's profits and in consumer surplus, the FTA members optimally choose regime $C N$ with $\phi^{*}=\phi_{c n 2}$. In this case, rents are actually shifted from firm $I$ to firm $E$ by requiring stringent ROO for firm $I$. Simultaneously, rents are shifted back from firm $E$ by imposing tariffs. When $\alpha>9 / 2$, implying that firm $I$ 's cost disadvantage is relatively small, such double rent-shifting is beneficial to the FTA members.

Note that for $k>2$, firm $I$ 's profits are actually higher in regime $C N$ with $\phi^{*}=\phi_{c n 2}$ than in regime $C C$. Therefore, in that case, rents are shifted from firm $E$ to firm $I$ as well as through tariff revenue.

\section{Conclusion}

In this paper, we analyzed the optimal choice of ROO in an FTA when the market structure is an international duopoly and an importing country in the FTA sets the unilaterally optimal external tariffs subject to the constraint of GATT Article XXIV. We considered a case in which an internal firm has inferior production technology to an external firm but has an advantage with respect to the ROO-related compliance costs. In such a situation, we show that the optimal ROO may have a protectionist bias in the sense that only the internal firm has an incentive to comply with them. Optimal ROO may also be set so that even the internal firm has no incentive to comply with them. These outcomes depend on parameter values of the relative cost disadvantage of the internal firm and the relative disadvantage of the external firm in compliance costs. The optimal ROO has a protectionist bias if the marginal production cost of the internal firm is sufficiently higher than that of the external firm or if the compliance costs of the external firm are sufficiently higher than those 
of the internal firm. On the other hand, the optimal ROO leads to low utilization of the FTA by the internal firm if the cost disadvantage of the internal firm is at a medium level and the degree of the external firm's disadvantage in compliance costs is low.

Unlike previous studies in the literature of ROO, we constructed a simple model by abstracting the intermediate-good market and directly introduced compliance costs of ROO into firms' cost functions. This simple approach allowed us to derive the optimal ROO with the external tariff imposed by an importing country within an FTA.

Our model can be extended in various ways. For example, one can investigate the optimal choice of ROO when there is a two-way trade between the members of the FTA and both countries set their individual external tariffs. One can also examine the effects of multilateral tariff negotiations prior to the formation of the FTA on the optimal choice of ROO by setting a tariff ceiling. These extensions constitute our future work. 


\section{Appendix A Proof of Proposition 1}

In stage 3 , each firm chooses compliance, $C$, or non-compliance, $N$. Thus, the game in stage 3 can be represented by the normal form game shown in Table 1.

Table 1: A normal form representation of stage 3

Firm $E$

\begin{tabular}{cc|cc|cc|}
\multicolumn{2}{c}{ Firm $I$} & $\mathrm{C}$ & \multicolumn{2}{c}{$\mathrm{C}$} & \multicolumn{1}{c}{$\mathrm{N}$} \\
\cline { 3 - 5 } & $\mathrm{N}$ & $\pi_{c c}^{I}$, & $\pi_{c c}^{E}$ & $\pi_{c n}^{I}$, & $\pi_{c n}^{E}$ \\
\cline { 3 - 5 } & $\pi_{n c}^{I}$, & $\pi_{n c}^{E}$ & $\pi_{n n}^{I}$, & $\pi_{n n}^{E}$ \\
\cline { 3 - 5 } & & &
\end{tabular}

Firms' best responses can be found in the following way. First, for firm $I$, Eqs. (11) and (17) yield

$$
\pi_{c c}^{I}-\pi_{n c}^{I}=\frac{4(a-2 c-t+(k-1) \phi)(t-\phi)}{9} .
$$

Thus, $\pi_{c c}^{I} \geq \pi_{n c}^{I}$ holds if and only if $\phi \leq t$. Moreover, from Eqs. (4) and (15), we have

$$
\pi_{n n}^{I}-\pi_{c n}^{I}=\frac{4(a-2 c-\phi)(\phi-t)}{9},
$$

which implies that $\pi_{n n}^{I} \geq \pi_{c n}^{I}$ holds if and only if $\phi \geq t$. Second, for firm $E$, Eqs. (11) and (15) yield

$$
\pi_{c c}^{E}-\pi_{c n}^{E}=\frac{4(a+c-t-(k-1) \phi)(t-k \phi)}{9} .
$$

Thus, $\pi_{c c}^{E} \geq \pi_{c n}^{E}$ holds if and only if $\phi \leq t / k$. Similarly, from Eqs. (4) and (17), it follows that

$$
\pi_{n n}^{E}-\pi_{n c}^{E}=\frac{4(a+c-k \phi)(k \phi-t)}{9},
$$

yielding that $\pi_{n n}^{E} \geq \pi_{n c}^{E}$ if and only if $\phi \geq t / k$.

Then, when $0 \leq \phi<t / k, C$ is the dominant strategy for both firms; hence, $\{C, C\}$ is a unique NE as long as $\varepsilon>0$ is sufficiently small. When $t / k \leq \phi<t, C$ is still the dominant strategy for firm $I$, and $N$ is the dominant strategy for firm $E$ in the presence of $\varepsilon>0$. Thus, $\{C, N\}$ is a unique NE. Finally, when $t \leq \phi, N$ becomes the dominant strategy for both firms in the presence of $\varepsilon>0$. Thus, $\{N, N\}$ is a unique NE.

\section{Appendix B Proof of Lemma 5}

(i) For $5 / 2<\alpha \leq 43 / 14, \phi_{c n}=t$ holds for $\phi_{c n}=\phi_{b}=(2 a-c) / 8$, and $t=t_{b}=(2 a-c) / 8$, and $\phi_{c n}=t / k$ holds for $\phi_{c n}=\phi_{c n 2}=(a+4 c) /(11 k-4)$ and $t=t_{c n}\left(\phi_{c n 2}\right)=(a+4 c) k /(11 k-4)$. Comparing joint welfare of the FTA members in these cases, Eqs. (27) and (30) yield

$$
\begin{aligned}
W_{c n}^{A B}\left(\phi_{b}\right)-W_{c n}^{A B}\left(\phi_{c n 2}\right)= & -\frac{1}{8(11 k-4)^{2}}[(2 a-3 c) k\{(53 a-19 c) k-8(8 a+11 c)\} \\
& +12(a+2 c)(3 a-2 c)] .
\end{aligned}
$$


It can be shown that the term within the curly brackets on the RHS of Eq. (A.1) is negative if (32) holds, which implies that $W_{c n}^{A B}\left(\phi_{b}\right)>W_{c n}^{A B}\left(\phi_{c n 2}\right)$. Otherwise, the this term is non-negative; hence, $W_{c n}^{A B}\left(\phi_{b}\right) \leq W_{c n}^{A B}\left(\phi_{c n 2}\right)$ holds. As the RHS of (32) becomes one when $\alpha=3$ and a complex number for $\alpha<3, \phi_{c n}=\phi_{b}=(2 a-c) / 8$ never holds for $\alpha \leq 3$.

(ii) For $43 / 14<\alpha, \phi_{c n}=t$ holds when $\phi_{c n}=\phi_{b}=(2 a-c) / 8$ for $\alpha \leq 13 / 2$ and $\phi_{c n}=\phi_{c n 1}=$ $(a+4 c) / 7$ for $13 / 2<\alpha$. On the other hand, $\phi_{c n}=t / k$ holds when $\phi_{c n}=\phi_{b} / k=(2 a-c) / 8 k$ for $43 / 14<\alpha<13 / 2$ and $k<4(2 \alpha-1) /(14 \alpha-43)$ and $\phi_{c n}=\phi_{c n 2}=(a+4 c) /(11 k-4)$ for $k \geq 4(2 \alpha-1) /(14 \alpha-43)$. Note that $4(2 \alpha-1) /(14 \alpha-43)=1$ holds at $\alpha=13 / 2$. Thus, for $43 / 14<\alpha \leq 13 / 2$, we compare joint welfare of the FTA members at $\phi_{c n}=\phi_{b}=(2 a-c) / 8$ and $\phi_{c n}=\phi_{b} / k=(2 a-c) / 8 k$. From Eqs. (27) and (31), we have

$$
W_{c n}^{A B}\left(\phi_{b}\right)-W_{c n}^{A B}\left(\phi_{b} / k\right)=-\frac{(k-1)(2 a-c)\{(26 a-45 c) k-3(2 a-c)\}}{384 k^{2}} .
$$

Since $3(2 \alpha-1) /(26 \alpha-45)<1$ holds for $\alpha>5 / 2$, it follows that $W_{c n}^{A B}\left(\phi_{b}\right)<W_{c n}^{A B}\left(\phi_{b} / k\right)$; hence, $\phi_{c n}=\phi_{b}=(2 a-c) / 8$ does not hold. Moreover, a comparison of joint welfare of countries A and $\mathrm{B}$ under $\phi_{c n}=\phi_{b}=(2 a-c) / 8$ and $\phi_{c n}=\phi_{b} / k=(2 a-c) / 8 k$ has been made in Eq. (A.1). However, it is shown that

$$
\frac{4(2 \alpha-3)(8 \alpha+11)+2(\alpha+4) \sqrt{35(2 \alpha-3)(\alpha-3)}}{(2 \alpha-3)(53 \alpha-19)}<\frac{4(2 \alpha-1)}{(14 \alpha-43)}
$$

holds for all $\alpha \in(43 / 14,13 / 2)$. Thus, $W_{c n}^{A B}\left(\phi_{b}\right)<W_{c n}^{A B}\left(\phi_{c n 2}\right)$ holds. It follows that $\phi_{c n}=\phi_{b}=$ $(2 a-c) / 8$ is never optimal in this case. Finally, for $13 / 2<\alpha$, comparing joint welfare of countries A and B under $\phi_{c n}=\phi_{c n 1}=(a+4 c) / 7$ and $\phi_{c n}=\phi_{c n 2}=(a+4 c) /(11 k-4)$, Eqs. (26) and (30) yield

$$
W_{c n}^{A B}\left(\phi_{c n 1}\right)-W_{c n}^{A B}\left(\phi_{c n 2}\right)=-\frac{5(k-1)(a+4 c)\{(25 a-54 c) k-(11 a-12 c)\}}{14(11 k-4)^{2}} .
$$

Thus, if

$$
k<\frac{11 a-12 c}{25 a-54 c}=\frac{11 \alpha-12}{25 \alpha-54},
$$

then $W_{c n}^{A B}\left(\phi_{c n 1}\right)>W_{c n}^{A B}\left(\phi_{c n 2}\right)$ holds. However, since $(11 \alpha-12) /(25 \alpha-54)<1$ holds for $\alpha>3$, $W_{c n}^{A B}\left(\phi_{c n 1}\right)<W_{c n}^{A B}\left(\phi_{c n 2}\right)$ holds in the relevant range of the parameter values.

\section{Appendix C Proof of Proposition 2}

(i) From Eqs. (20) and (30), we have

$$
\begin{aligned}
W_{c n}^{A B}\left(\phi_{c n 2}\right)-W_{n n}^{A B}\left(t_{b}\right)= & \frac{1}{64(11 k-4)^{2}}\left\{\left(364 a^{2}-124 a c-149 c^{2}\right) k^{2}-8\left(84 a^{2}+116 a c-319 c^{2}\right) k\right. \\
& \left.+224 a^{2}+576 a c-464 c^{2}\right\} .
\end{aligned}
$$

Then, it can be shown that, if (37) holds, the term within the curly brackets on the RHS of Eq. (A.2) is negative and, hence, it follows that $W_{c n}^{A B}\left(\phi_{c n 2}\right)<W_{n n}^{A B}\left(t_{b}\right)$. In (37), $28 \alpha^{2}-108 \alpha+87=0$ when 
$\alpha=(27+2 \sqrt{30}) / 14 \approx 2.71$ and $28 \alpha^{2}-108 \alpha+87<0$ for $\alpha<(27+2 \sqrt{30}) / 14$. Thus, (37) does not hold for $\alpha \leq(27+2 \sqrt{30}) / 14$. From Eqs. (20) and (27), we have

$$
W_{n n}^{A B}\left(t_{b}\right)-W_{c n}^{A B}\left(\phi_{b}\right)=\frac{(2 a-c)(2 a-5 c)}{64} .
$$

Thus, $W_{c n}^{A B}\left(\phi_{b}\right)<W_{n n}^{A B}\left(t_{b}\right)$ always holds for $\alpha>5 / 2$.

(ii) For $43 / 14<\alpha<9 / 2$, from Lemma $5, \phi_{c n}=\phi_{c n 2}$ if (34) holds, and $\phi_{c n}=\phi_{b} / k$ if (33) holds. Eqs. (20) and (31) yield

$$
W_{c n}^{A B}\left(\phi_{b} / k\right)-W_{n n}^{A B}\left(t_{b}\right)=\frac{(2 a-c)\left\{(14 a-15 c) k^{2}-16(2 a-3 c) k+3(2 a-c)\right\}}{384 k^{2}} .
$$

It can be shown that if (38) holds, it follows that $W_{c n}^{A B}\left(\phi_{b} / k\right)>W_{n n}^{A B}\left(t_{b}\right)$. On the other hand, Eqs. (20) and (30) yield

$$
\begin{aligned}
W_{c n}^{A B}\left(\phi_{c n 2}\right)-W_{n n}^{A B}\left(t_{b}\right)= & \frac{1}{64(11 k-4)^{2}}\left\{\left(364 a^{2}-124 a c-149 c^{2}\right) k^{2}-8\left(84 a^{2}+116 a c-319 c^{2}\right) k\right. \\
& \left.+224 a^{2}+576 a c-464 c^{2}\right\} .
\end{aligned}
$$

Thus, if (39) holds, it follows that $W_{c n}^{A B}\left(\phi_{c n 2}\right)>W_{n n}^{A B}\left(t_{b}\right)$. Note that for $43 / 14<\alpha<9 / 2,4(2 \alpha-$ 1)/(14 -43$)$ is monotonically decreasing, and the RHS of both (38) and (39) is monotonically increasing, and all three take the same value at $\alpha=(323+16 \sqrt{205}) / 126 \approx 4.38$.

(iii) For $\alpha>9 / 2$, from Lemma 5 , regime $C N$ has two possible optimal ROO solutions: $\phi_{c n}=\phi_{b} / k$ and $\phi_{c n}=\phi_{c n 2}$. Eqs. (30) and (36) yield

$$
W_{c n}^{A B}\left(\phi_{c n 2}\right)-W_{c c}^{A B}\left(\phi_{c c}=0\right)=\frac{(a+4 c)\left\{(19 a-12 c) k^{2}-2(26 a-33 c) k+19 a-12 c\right\}}{6(11 k-4)^{2}} .
$$

Thus, if Eq. (40) holds, it follows that $W_{c n}^{A B}\left(\phi_{c n 2}\right)>W_{c c}^{A B}\left(\phi_{c c}=0\right)$. Note that the RHS of Eq. (40) becomes $(8+\sqrt{15}) / 7 \approx 1.70$ at $\alpha=9 / 2$ and is increasing for $\alpha>9 / 2$. Moreover, Eqs. (31) and (36) yield

$$
W_{c n}^{A B}\left(\phi_{b} / k\right)-W_{c c}^{A B}\left(\phi_{c c}=0\right)=\frac{1}{384 k^{2}}(2 a-c)\left\{(10 a+3 c) k^{2}-16(2 a-3 c) k+3(2 a-c)\right\} .
$$

Thus, if

$$
k \geq \frac{8(2 \alpha-3)+\sqrt{(14 \alpha-15)(14 \alpha-39)}}{10 \alpha+3}
$$

holds, it follows that $W_{c n}^{A B}\left(\phi_{b} / k\right) \geq W_{c c}^{A B}\left(\phi_{c c}=0\right)$. Note that the RHS of (A.4) becomes $1+$ $\sqrt{1152} / 48 \approx 1.71$ at $\alpha=9 / 2$, and it is increasing for $\alpha>9 / 2$. On the other hand, from Lemma 5 , if (34) holds, then $\phi_{c n}=\phi_{c n 2}$. Note that the RHS of (34) becomes $4(2 \alpha-1) /(14 \alpha-43)=1.6$ at $\alpha=9 / 2$ and is decreasing for $\alpha>9 / 2$. 


\section{References}

Andreoni, J., B. Erard and J. Feinstein (1998) "Tax compliance", Journal of Economic Literature, Vol. 36, No. 2, pp. 818-860.

Anson, J., O. Cadot, A. Estevadeordal, J. de Melo, A. Suwa-Eisenmann and B. Tumurchudur (2005) "Rules of origin in North-South preferential trading arrangements with an application to NAFTA", Review of International Economics, Vol. 13, No. 3, pp. 501-517.

Augier, P., M. Gasiorek and C. Lai Tong (2005) "The impact of rules of origin on trade flows", Economic Policy, Vol. 20, No. 43, pp. 567-624.

Cadot, O. and J. de Melo (2008) "Why OECD countries should reform rules of origin", World Bank Research Observer, Vol. 23, No. 1, pp. 77-105.

Chang, Y. M. and R. Xiao (2013) "Free trade areas, the limit of rules of origin, and optimal tariff reductions under international oligopoly: A welfare analysis", Journal of International Trade 83 Economic Development, Vol. 22, No. 5, pp. 694-728.

Falvey, R. and G. Reed (1998) "Economic effects of rules of origin", Weltwirtschaftliches Archiv, Vol. 134, No. 2, pp. 209-229.

- and - (2002) "Rules of origin as commercial policy instruments", International Economic Review, Vol. 43, No. 2, pp. 393-407.

Hayakawa, K., D. Hiratsuka, K. Shiino and S. Sukegawa (2013) "Who uses free trade agreements?", Asian Economic Journal, Vol. 27, No. 3, pp. 245-264.

Ishikawa, J., H. Mukuniki and Y. Mizogushi (2007) "Economic integration and rules of origin under international oligopoly", International Economic Review, Vol. 48, No. 1, pp. 185-210.

James, W. E. (2008) "Rules of origin in emerging Asia-Pacific preferential trade agreements: Will PTAs promote trade and development?", in Asia-Pacific Research and Training Network on Trade, ed., Trade Facilitation beyond the Multilateral Trade Negotiations: Regional Practices, Customs Valuation and Other Emerging Issues, Bangkok: United Nations ESCAP, pp. 137-162.

Ju, J. and K. Krishna (2005) "Firm behaviour and market access in a Free Trade Area with Rules of Origin", Canadian Journal of Economics, Vol. 38, No. 1, pp. 290-308.

Krishna, K. and A. O. Krueger (1995) "Implementing free trade agreements: Rules of origin and hidden protection", in Deardorff, A. V., J. Levinsohn and R. M. Stern, eds., New Directions in Trade Theory, Ann Arbor: University of Michigan Press, pp. 149-187. 
Krueger, A. O. (1999) "Free trade agreements as protectionist devices: rules of origin", in Melvin, J. R., J. C. Moore and R. Riezman, eds., Trade, Theory and Econometrics: Essays in Honor of John Chipman, London: Routledge Press, pp. 91-101.

Lopez-de-Silanes, F., J. R. Markusen and T. F. Rutherford (1996) "Trade policy subtleties with multinational firms", European Economic Review, Vol. 40, pp. 1605-1627.

Mathieu, L., C. Waddams Price and F. Antwi (2010) "The distribution of UK personal income tax compliance costs", Applied Economics, Vol. 42, pp. 351-368.

Rosellón, J. (2000) "The Economics of Rules of Origin", Journal of International Trade \& Economic Development, Vol. 9, No. 4, pp. 397-425.

Takauchi, K. (2014) "Rules of origin and strategic choice of compliance", Journal of Industry, Competition, and Trade, Vol. 14, No. 2, pp. 287-302.

Tran-Nam, B., C. Evans, M. Walpole and K. Ritchie (2000) "Tax compliance costs: research methodology and empirical evidence from Australia", National Tax Journal, Vol. 53, No. 2, pp. 229252. 